\title{
Patterns of Hemodialysis Catheter Dysfunction Defined According to National Kidney Foundation Guidelines As Blood Flow $<300 \mathrm{~mL} / \mathrm{min}$
}

\author{
Robert I. Griffiths, ${ }^{1,2}$ Britt B. Newsome, ${ }^{3}$ Geoffrey A. Block, ${ }^{3}$ Robert J. Herbert, ${ }^{4}$ \\ and Mark D. Danese ${ }^{1}$ \\ ${ }^{1}$ Department of Epidemiology, Outcomes Insights, Inc., Westlake Village, CA 91362, USA \\ ${ }^{2}$ Division of General Internal Medicine, Johns Hopkins University School of Medicine, Baltimore, MD 21205-2109, USA \\ ${ }^{3}$ Department of Clinical Research, Denver Nephrologists, Denver, CO 80230, USA \\ ${ }^{4}$ Department of Health Policy and Management, Johns Hopkins Bloomberg School of Public Health, Baltimore, \\ MD 21205-2103, USA
}

Correspondence should be addressed to Robert I. Griffiths, bob@outins.com

Received 18 August 2011; Accepted 19 September 2011

Academic Editor: Alejandro Martín-Malo

Copyright $\odot 2011$ Robert I. Griffiths et al. This is an open access article distributed under the Creative Commons Attribution License, which permits unrestricted use, distribution, and reproduction in any medium, provided the original work is properly cited.

Blood flow rate $(\mathrm{BFR})<300 \mathrm{~mL} / \mathrm{min}$ commonly is used to define hemodialysis catheter dysfunction and the need for interventions to prevent complications. The objective of this study was to describe patterns of unplanned BFR $<300 \mathrm{~mL} / \mathrm{min}$ during catheter hemodialysis using data from DaVita dialysis facilities and the United States Renal Data System. Patients were included if they received at least eight weeks of hemodialysis exclusively through a catheter between 08/04 and 12/06, and catheter hemodialysis was the first treatment modality following diagnosis of end-stage renal disease (first access), or it immediately followed at least one 30 -day period of dialysis exclusively through a fistula or graft (replacement access). Actual BFR $<300 \mathrm{~mL} / \mathrm{min}$ despite a planned $\mathrm{BFR} \geq 300 \mathrm{~mL} / \mathrm{min}$ defined catheter dysfunction during each dialysis session. There were 3,364 patients, 268,363 catheter dialysis sessions, and 19,118 (7.1\%) sessions with catheter dysfunction. Almost two-thirds of patients had $\geq 1$ catheter dysfunction session, and $30 \%$ had $\geq 1$ catheter dysfunction session per month. Patients with catheter as a replacement access had a higher rate of catheter dysfunction than those with a catheter as first access (hazard ratio: 1.13; $P=0.04$ ). Catheter dysfunction affects almost one-third of catheter dialysis patients each month and two-thirds overall.

\section{Introduction}

Hemodialysis catheter dysfunction often is defined as blood flow rate (BFR) $<300 \mathrm{~mL} / \mathrm{min}$ [1], including in the National Kidney Foundation's Kidney Disease Outcome Quality Initiative (NKF-KDOQI) clinical practice guidelines [2]. Other definitions of catheter dysfunction reported in the literature include frequent arterial and venous pressure alarms, poor conductance, and poor dialysis efficiency based on urea reduction ratio or $\mathrm{Kt} / \mathrm{V}$ calculations [3-8]. Among these definitions, the one recommended by NKF-KDOQI may be of particular significance to providers and payers. This is especially true in the United States, where NKF-KDOQI guidelines play a prominent role in shaping clinical practice, including through the Centers for Medicare and Medicaid Services' (CMS) End-Stage Renal Disease (ESRD) Clinical Performance Measures Project [9]. Since the recommendation to define catheter dysfunction as BFR $<300 \mathrm{~mL} / \mathrm{min}$ was opinion based, concerns have been raised that it has been interpreted to mean BFR must be kept above $300 \mathrm{~mL} / \mathrm{min}$ to maintain adequate dialysis. However, one recent study showed that mean blood flows $<300 \mathrm{~mL} / \mathrm{min}$ were not commonly associated with dialysis inadequacy [1], prompting the authors to conclude that this definition of catheter dysfunction could result in a significant number of unnecessary interventions.

Presently, there is very little information on the epidemiology of hemodialysis catheter dysfunction defined as 
BFR $<300 \mathrm{~mL} / \mathrm{min}$. One exception is a study by Moist and colleagues on the association between BFR and dialysis adequacy, which found that mean blood flow $<300 \mathrm{~mL} / \mathrm{min}$ occurred in $10 \%$ of patients [1]. However, this was a cross-sectional study of only 259 patients conducted at two university-based tertiary hemodialysis care programs. Data on BFR are not present in the United States Renal Data System (USRDS), and they are not collected as part of the CMS ESRD Clinical Performance Measures Project. Without first understanding the epidemiology of catheter dysfunction defined according to NKF-KDOQI guidelines, it is difficult to assess the potential impact of this guideline on clinical outcomes and on interventions, both necessary and unnecessary.

The objective of this study was to describe patterns of hemodialysis catheter dysfunction, defined as unplanned BFR $<300 \mathrm{~mL} / \mathrm{min}$, in a large cohort of ESRD patients.

\section{Methods}

2.1. Study Design and Setting. An observational cohort study was performed using clinical and administrative data from DaVita Inc., merged with administrative and Medicare claims data from the USRDS. DaVita owns and operates more than 1,400 outpatient dialysis facilities in the United States and has acute units in more than 700 hospitals. Facilities are located in 43 states and the District of Columbia. Nationwide, DaVita serves approximately 110,000 patients. The DaVita clinical data warehouse is a repository for detailed demographic, treatment, medication, and laboratory information. Information is available for each patient's individual dialysis sessions, allowing the investigator to reconstruct detailed longitudinal treatment histories.

The USRDS is a national data system that collects, analyzes, and distributes information about ESRD in the United States [10]. It contains demographic, diagnosis, and treatment history information for all Medicare beneficiaries with ESRD, a point-prevalent cohort of approximately 570,000 in the second quarter of 2009 [11]. Also, it contains $100 \%$ of Medicare inpatient and outpatient bills for these patients. Presently, Medicare Part D oral medication claims are not included.

The data set used in this project was composed of a pointprevalent dialysis patient population in August 2004, with a maximum follow-up period through December 31, 2006.

2.2. Participants. Patients meeting the following criteria were included in this study: they received at least eight continuous weeks of hemodialysis exclusively through a catheter between August 1, 2004, and December 31, 2006; either catheter hemodialysis was their first treatment modality following diagnosis of ESRD (catheter as first access), or catheter hemodialysis immediately followed at least one month during which the patient was dialyzed exclusively through an arteriovenous fistula or graft (catheter as replacement access); in the first eight weeks of catheter dialysis, they did not have a gap between two consecutive outpatient dialysis sessions $>30$ days during which time they were not hospitalized; they had both Part A and Part B Medicare coverage during the entire catheter dialysis period; they did not have a kidney transplant during the entire catheter dialysis period; at least $95 \%$ of their catheter dialysis sessions had actual and planned blood flow rates between $100 \mathrm{~mL} / \mathrm{min}$ and $500 \mathrm{~mL} / \mathrm{min}$; they were alive and in the data set for at least 90 days following the first catheter dialysis session. Planned and actual BFR values $<100 \mathrm{~mL} / \mathrm{min}$ or $>500 \mathrm{~mL} / \mathrm{min}$ were set to missing to minimize the potential impact of coding errors. In the final cohort, $99.9 \%$ of BFR values were within this range. The observation period was defined as beginning at the first catheter dialysis session and ending at the last catheter dialysis session that was uninterrupted by either a change in access or dialysis modality.

2.3. Variables. Using DaVita data, we reconstructed a longitudinal history of catheter dialysis treatments for each patient during their observation period. Reasons for reaching the end of the observation period were defined as (a) death, if the patient died on or before December 31,2006, and if the last catheter dialysis session was within 30 days of death, (b) end of data (censored), if the last catheter dialysis session was within 30 days of December 31, 2006, or (c) change in access type or modality, if the last observed catheter dialysis session was not due to either death or the end of the data.

The primary outcome variable was catheter dysfunction, which was defined as actual BFR $<300 \mathrm{~mL} / \mathrm{min}$ despite a planned BFR $\geq 300 \mathrm{~mL} / \mathrm{min}$. Actual BFR was measured approximately one hour after the beginning of the dialysis session. We elected to make our definition of catheter dysfunction more restrictive than in the NKF/KDOQI clinical practice guidelines for vascular access to eliminate misclassification of catheter dysfunction where the intent, as indicated by planned BFR, was to provide $\mathrm{BFR}<300 \mathrm{~mL} / \mathrm{min}$.

Medical resource and cost outcome variables in this study were total direct medical costs to Medicare, missed dialysis sessions due to access problems, access-related procedures, and all-cause hospitalization. The DaVita data contained a record for each missed session. Each record had the date of the missed session and the reason for the missed session, including "access problems." Access-related procedures were identified using the Medicare claims data, based on the following Health Care Common Procedure Coding System (HCPCS) codes: injection for catheter evaluation with fluoroscopy (36598); thrombolytic declotting of catheter (36593); mechanical removal of clot (36596); mechanical removal of intraluminal (intracatheter) obstructive material (75902); injection of "TPA" (J2997); tunneled catheter exchange or replacement (36581); the combination of removal of tunneled catheter (36589) plus tunneled catheter insertion (36558). Hospitalizations consisted of all acute care admissions for any reason and were identified from the Medicare claims.

2.4. Analyses. Patients were described according to their demographic and clinical characteristics at the time they began catheter dialysis, including age, gender, race, underlying cause of renal failure, dialysis vintage, ESRD network, Charlson Comorbidity Index [12], and whether catheter was their first dialysis access or a replacement for a graft or 
TABLE 1: Patient characteristics.

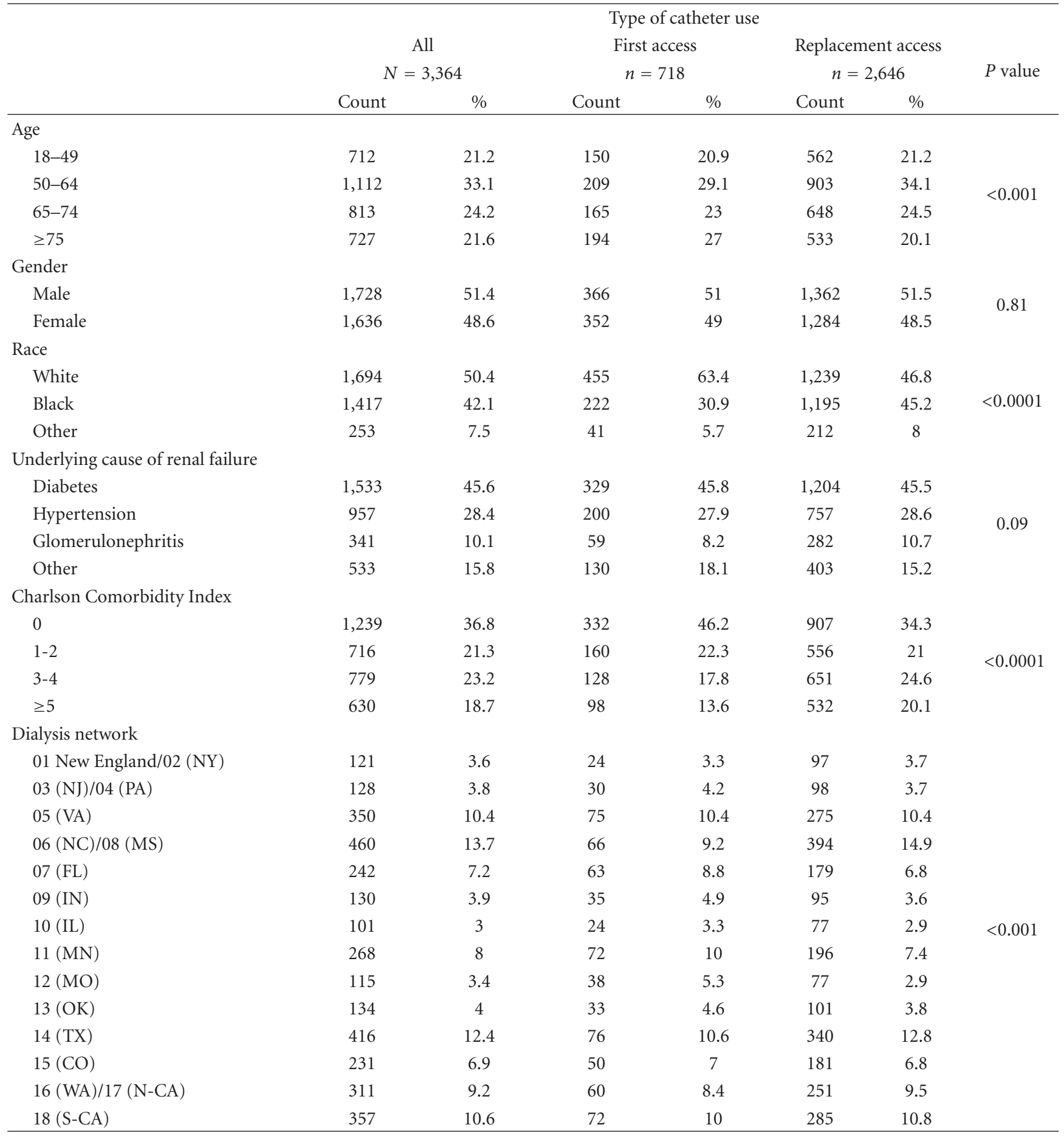

fistula. Multivariate analysis with Cox's proportional hazards model was used to examine adjusted associations between patient factors and the risk of catheter dysfunction. For the medical resource and cost analyses, patients with at least one catheter dysfunction session were divided into quintiles based on the number of catheter dysfunction sessions per month on catheter dialysis. Medical resource use and costs were compared, unadjusted, across the five groups. Analysis file construction and all analyses were performed in SAS (version 9.1.3) [13].

\section{Results}

There were 3,364 patients who met the inclusion and exclusion criteria. The average age was 62 years, $51 \%$ were male gender, $42 \%$ were black race, $46 \%$ had diabetes, and 
TABLE 2: Catheter dysfunction*.

\begin{tabular}{|c|c|c|c|c|c|}
\hline & \multirow{2}{*}{$\begin{array}{l}\text { All patients } \\
N=3,364\end{array}$} & \multirow{2}{*}{$\begin{array}{c}\text { Catheter as } \\
\text { first access } \\
N=718\end{array}$} & \multicolumn{3}{|c|}{ Catheter as replacement access } \\
\hline & & & $\begin{array}{c}\text { All } \\
N=2,646\end{array}$ & $\begin{array}{c}\text { Graft } \\
N=1,758\end{array}$ & $\begin{array}{c}\text { Fistula } \\
N=888\end{array}$ \\
\hline Patient months & 23,045 & 5,663 & 17,382 & 11,579 & 5,803 \\
\hline Catheter sessions & 268,363 & 66,285 & 202,078 & 134,250 & 67,828 \\
\hline Patients with $\geq 1 \mathrm{CD}$ session & 2,132 & 454 & 1,678 & 1,123 & 555 \\
\hline$\%$ Patients with $\geq 1 \mathrm{CD}$ session & $63 \%$ & $63 \%$ & $63 \%$ & $64 \%$ & $63 \%$ \\
\hline Median time (days) to 1 st $\mathrm{CD}$ session & 95 & 105 & 94 & 89 & 108 \\
\hline Total CD sessions & 19,118 & 4,024 & 15,094 & 10,085 & 5,009 \\
\hline Rate of CD per patient month at risk & 0.83 & 0.71 & 0.87 & 0.87 & 0.86 \\
\hline $\begin{array}{l}\text { Mean \# CD sessions among patients } \\
\text { with } \geq 1 \mathrm{CD} \text { session }\end{array}$ & 9.0 & 8.9 & 9.0 & 9.0 & 9.0 \\
\hline
\end{tabular}

${ }^{*}$ Catheter dysfunction was defined as unplanned blood flow rate during the dialysis session of $<300 \mathrm{~mL} / \mathrm{min}$. CD: catheter dysfunction.

$28 \%$ had hypertension reported as the underlying cause of renal failure (Table 1). Patients with catheter as a replacement access were older, had been diagnosed with ESRD for a longer period of time, and had higher Charlson Comorbidity Index scores [12]. Those with catheter as first access were more likely to be white race. Within the catheter as replacement group, patients with catheter replacing a graft were older, had higher Charlson Comorbidity Index scores, and were more likely to be female gender and black race, compared to those with catheter replacing a fistula.

Overall, the median duration of catheter dialysis in the cohort was 143 days, the first 56 days of which were mandated by the eligibility criteria. The median duration of catheter dialysis was significantly longer for those with catheter as first access compared to replacement access (159 days versus 138 days: $P<0.0001$ by Log Rank) (Figure 1). Among those with catheter as a replacement access, there was no difference between those with prior graft (median 139 days) and those with prior fistula (median 136 days: $P=0.84$ by Log Rank).

The cohort accounted for more than 23,000 patientmonths of catheter dialysis, with the majority in the catheter as replacement access group (Table 2). Almost twothirds of patients had at least one dialysis session with an unplanned BFR $<300 \mathrm{~mL} / \mathrm{min}$, the study definition of catheter dysfunction, during their entire catheter dialysis history. Proportions were similar between catheter as first and catheter as replacement access and between prior graft and prior fistula in the catheter replacement access group. The median time to first dialysis session with unplanned BFR $<300 \mathrm{~mL} / \mathrm{min}$ was longer, but not significantly longer ( $P=0.08$ by Log Rank) in the catheter as first access group (Figure 2). Also the rate per patient month at risk (Figure 3) and the percent of patients with at least one session per month with unplanned BFR $<300 \mathrm{~mL} / \mathrm{min}$ (Figure 4) were lower in the catheter as first access group, especially after the first 9 months of catheter dialysis. Patients with at least one session meeting the study definition of catheter dysfunction had, on average, nine sessions with unplanned BFR $<300 \mathrm{~mL} / \mathrm{min}$. (Table 2; Figure 5).

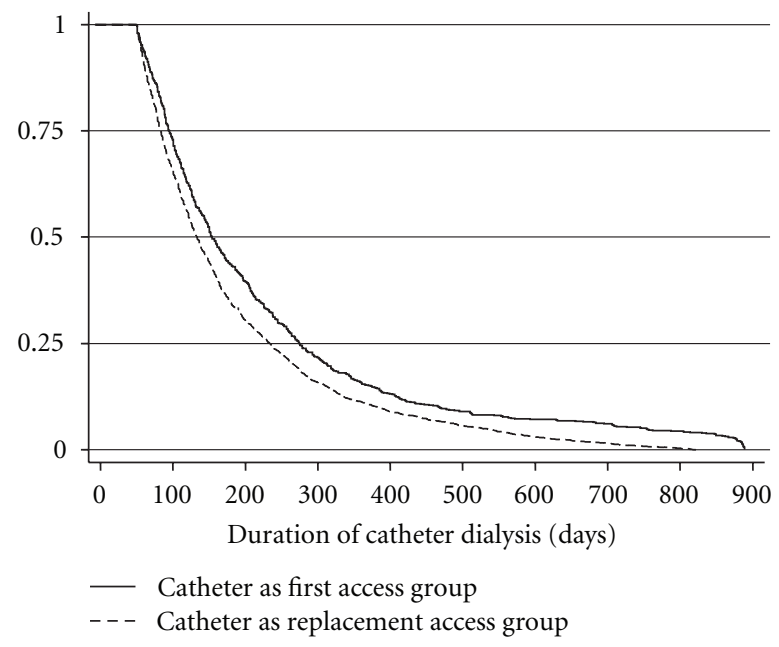

FIgURE 1: Duration of catheter dialysis.

In the multivariate analysis using Cox's proportional hazards model for time to first session with catheter dysfunction, male gender and black race (compared to white) were associated with lower rates of catheter dysfunction (Table 3 ). Catheter as replacement access following graft or fistula was associated with a significantly higher rate of catheter dysfunction than catheter as first access. There was also considerable variability in the rate of catheter dysfunction across ESRD networks.

Patients in the highest quintile of catheter dysfunction sessions per month had higher average monthly direct medical costs, more missed sessions due to access problems, and more access-related procedures than those in the lowest quintile (Table 4). Hospitalization rates were similar across the five groups.

\section{Discussion}

Little has been reported on the epidemiology of hemodialysis catheter dysfunction, commonly defined, including in 
TABLE 3: Factors associated with catheter dysfunction*.

\begin{tabular}{|c|c|c|c|c|}
\hline $\begin{array}{l}\text { Age } \\
\end{array}$ & Hazard ratio & \multicolumn{2}{|c|}{$95 \%$ confidence interval } & $P$ value \\
\hline$<50$ & & & & \\
\hline $50-64$ & 1.08 & 0.95 & 1.23 & 0.23 \\
\hline $65-74$ & 1.14 & 0.99 & 1.30 & 0.07 \\
\hline$\geq 75$ & 1.13 & 0.98 & 1.31 & 0.09 \\
\hline \multicolumn{5}{|l|}{ Gender } \\
\hline Female & \multicolumn{4}{|c|}{ Reference } \\
\hline Male & 0.85 & 0.78 & 0.92 & $<0.0001$ \\
\hline \multicolumn{5}{|l|}{ Race } \\
\hline White & \multicolumn{4}{|c|}{ Reference } \\
\hline Black & 0.90 & 0.82 & 1.00 & 0.04 \\
\hline Other & 0.98 & 0.83 & 1.17 & 0.84 \\
\hline \multicolumn{5}{|l|}{ Underlying cause of renal failure } \\
\hline Diabetes & \multicolumn{4}{|c|}{ Reference } \\
\hline Hypertension & 1.08 & 0.97 & 1.20 & 0.17 \\
\hline Glomerulonephritis & 0.99 & 0.85 & 1.16 & 0.94 \\
\hline Other/unknown & 1.01 & 0.88 & 1.15 & 0.95 \\
\hline \multicolumn{5}{|l|}{ Network } \\
\hline 6 and 8 & \multicolumn{4}{|c|}{ Reference } \\
\hline 1 and 2 & 0.52 & 0.40 & 0.68 & $<0.0001$ \\
\hline 3 & 0.67 & 0.51 & 0.87 & $<0.01$ \\
\hline 5 & 0.64 & 0.54 & 0.76 & $<0.0001$ \\
\hline 7 & 0.53 & 0.43 & 0.65 & $<0.0001$ \\
\hline 9 & 1.21 & 0.96 & 1.52 & 0.10 \\
\hline 10 & 1.23 & 0.95 & 1.57 & 0.11 \\
\hline 11 & 0.74 & 0.61 & 0.89 & $<0.01$ \\
\hline 12 & 0.70 & 0.54 & 0.91 & $<0.01$ \\
\hline 13 & 0.95 & 0.75 & 1.19 & 0.63 \\
\hline 14 & 0.89 & 0.76 & 1.05 & 0.16 \\
\hline 15 & 0.78 & 0.64 & 0.96 & 0.02 \\
\hline 16 & 0.77 & 0.64 & 0.92 & $<0.01$ \\
\hline 18 & 0.44 & 0.36 & 0.54 & $<.0001$ \\
\hline \multicolumn{5}{|l|}{ Charlson Comorbidity Index } \\
\hline 0 & \multicolumn{4}{|c|}{ Reference } \\
\hline $1-2$ & 0.87 & 0.71 & 1.06 & 0.16 \\
\hline $3-4$ & 0.91 & 0.76 & 1.07 & 0.25 \\
\hline$>4$ & 0.93 & 0.79 & 1.10 & 0.40 \\
\hline \multicolumn{5}{|l|}{ Replacement access } \\
\hline Catheter as first access & \multicolumn{4}{|c|}{ Reference } \\
\hline Catheter as replacement access & 1.13 & 1.01 & 1.27 & 0.04 \\
\hline
\end{tabular}

NKF-KDOQI guidelines, as BFR $<300 \mathrm{~mL} / \mathrm{min}$. Without understanding the epidemiology of catheter dysfunction so defined, it is not possible to assess the overall impact of the NKF-KDOQI guideline on clinical and economic outcomes. Presently, data on BFR are not collected within the USRDS, or as part of CMS's ESRD Clinical Performance Measures Project. Therefore, DaVita clinical data linked to Medicare administrative, and claims data provided a unique opportunity to examine catheter dysfunction in this population. We conducted an observational study in a large cohort of patients who accounted for more than 23,000 months of catheter dialysis and 268,000 catheter dialysis sessions. Although not intended to be a random sample of all ESRD patients undergoing catheter dialysis in the 
TABLE 4: Cost and resource use by number of catheter dysfunction sessions*.

\begin{tabular}{|c|c|c|c|c|c|}
\hline \multirow{2}{*}{$\begin{array}{l}\text { Catheter dysfunction } \\
\text { sessions/month (quintile) }\end{array}$} & \multirow[b]{2}{*}{ Patients $(n)$} & \multicolumn{4}{|c|}{ Cost and Resource Use } \\
\hline & & $\begin{array}{l}\text { Direct medical } \\
\text { cost** }\end{array}$ & $\begin{array}{l}\text { Missed sessions } \\
\text { due to access }{ }^{* * *}\end{array}$ & Hospitalization*** & $\begin{array}{c}\text { Catheter access } \\
\text { procedure*** }\end{array}$ \\
\hline $1(0.04-0.32)$ & 424 & $\$ 5,390$ & 1.2 & 19.2 & 21.3 \\
\hline $2(0.33-0.56)$ & 426 & $\$ 5,746$ & 1.4 & 25.8 & 26.7 \\
\hline $3(0.57-1.13)$ & 430 & $\$ 5,634$ & 1.9 & 23 & 29.9 \\
\hline $4(1.14-2.33)$ & 433 & $\$ 6,010$ & 2.3 & 26.4 & 42.4 \\
\hline $5(>2.33)$ & 419 & $\$ 6,226$ & 2.8 & 26.6 & 56.4 \\
\hline All & 2,132 & $\$ 5,801$ & 1.9 & 24.2 & 35.3 \\
\hline
\end{tabular}

* Catheter dysfunction was defined as unplanned blood flow rate during the dialysis session of $<300 \mathrm{~mL} / \mathrm{min}$.

** Per month on catheter dialysis.

*** Per 100 patient months at risk.

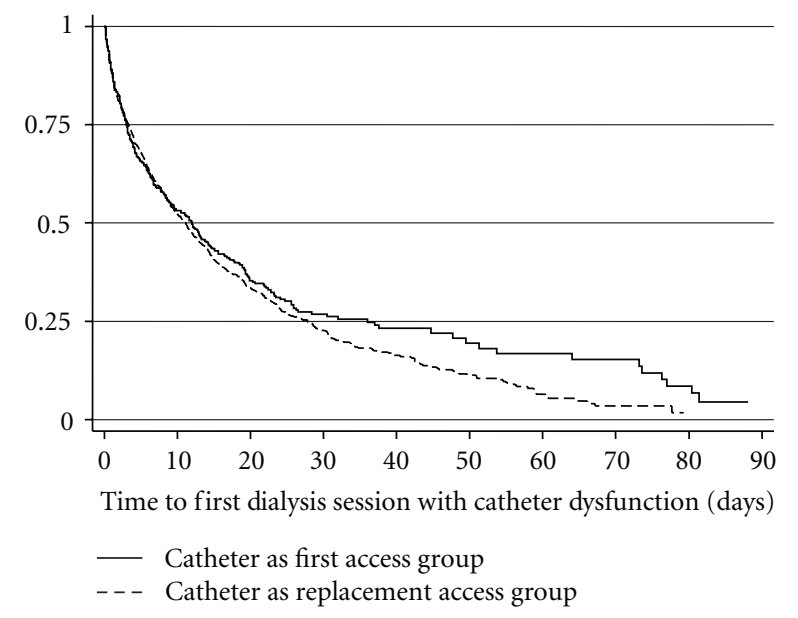

FIGURE 2: Time to first dialysis session with catheter dysfunction. Catheter dysfunction was defined as unplanned blood flow rate during the dialysis session of $<300 \mathrm{~mL} / \mathrm{min}$.

United States, our cohort was geographically diverse and demographically similar to the prevalent ESRD population in 2004, the year our study began.

Our findings indicate that unplanned BFR $<300 \mathrm{~mL} / \mathrm{min}$ is common, occurring at least once in almost two-thirds of patients who undergo catheter dialysis for more than eight weeks, and occurring in approximately one-third of patients every month. Further, the findings indicate that unplanned BFR $<300 \mathrm{~mL} / \mathrm{min}$ occurs in approximately $7 \%$ of all catheter dialysis sessions. Having catheter access as a replacement for a graft or fistula is associated with a higher risk of catheter dysfunction compared to catheter as the first type of access for dialysis. Also, having more catheter dysfunction sessions per month is associated with higher direct medical costs, interruptions or delays in dialysis services, and higher rates of catheter access procedures.

There are several possible reasons why the rates we observed may underestimate the true rates. First, we excluded sessions in which planned or actual BFR values were either $<100 \mathrm{~mL} / \mathrm{min}$ or $>500 \mathrm{~mL} / \mathrm{min}$. We did so to avoid misclassifying as catheter dysfunction sessions in which BFR values were misreported in the data. Second,

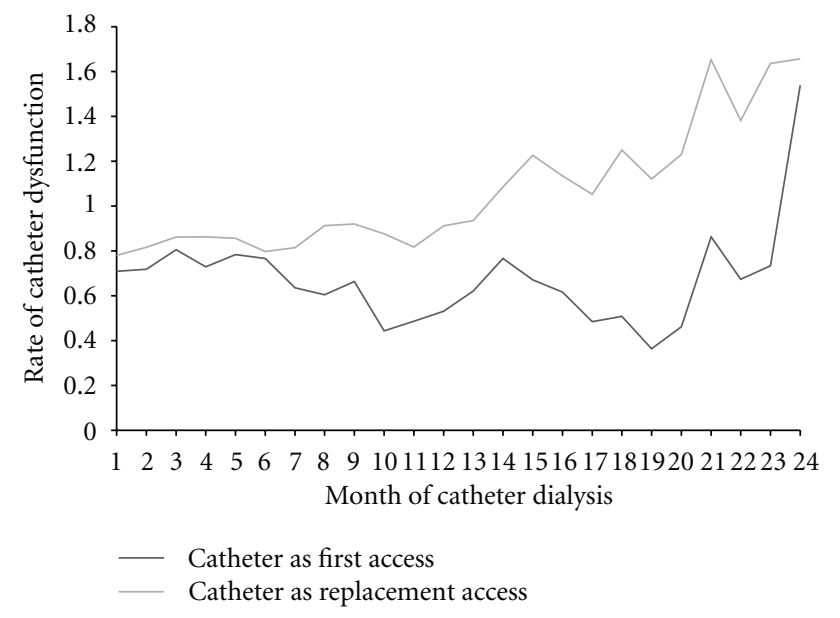

Figure 3: Rate of catheter dysfunction. Catheter dysfunction was defined as unplanned blood flow rate during the dialysis session of $<300 \mathrm{~mL} / \mathrm{min}$.

although NKF/KDOQI defines catheter dysfunction as BFR $<300 \mathrm{~mL} / \mathrm{min}$, our definition was more conservative because we also required the planned BFR to be $\geq 300 \mathrm{~mL} / \mathrm{min}$. Third, actual BFR was obtained from a single measurement approximately one hour after the beginning of the session. Fourth, by requiring patients to have at least eight weeks of catheter dialysis and to have survived at least 90 days following the start of dialysis, we excluded patients who were on catheter dialysis for shorter periods of time or who died within 90 days of beginning catheter dialysis. To the extent that catheter dysfunction is more common sooner after placement, by excluding patients with short-term catheter dialysis, we may have underestimated the overall rate of dysfunction. Catheter dysfunction due to mechanical reasons, which is known to occur sooner rather than later after placement, may be disproportionately underrepresented. Also, if death during the first 90 days after catheter placement is related to serious complications of catheter dysfunction, such as bloodstream infection, by requiring at least 90 -day survival, we may have underestimated the impact of catheter dysfunction on the use of medical services, in particular on all-cause hospitalization. 


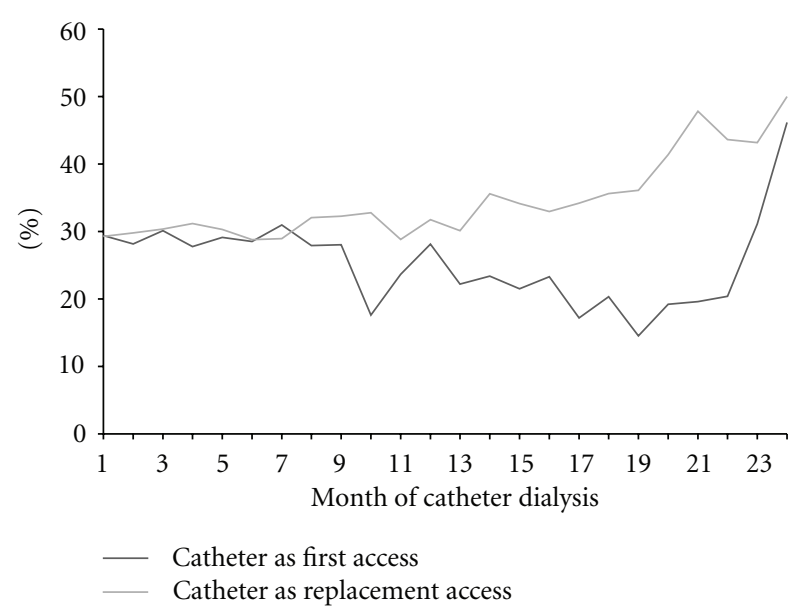

Figure 4: Percent of patients with catheter dysfunction. Catheter dysfunction was defined as unplanned blood flow rate during the dialysis session of $<300 \mathrm{~mL} / \mathrm{min}$.

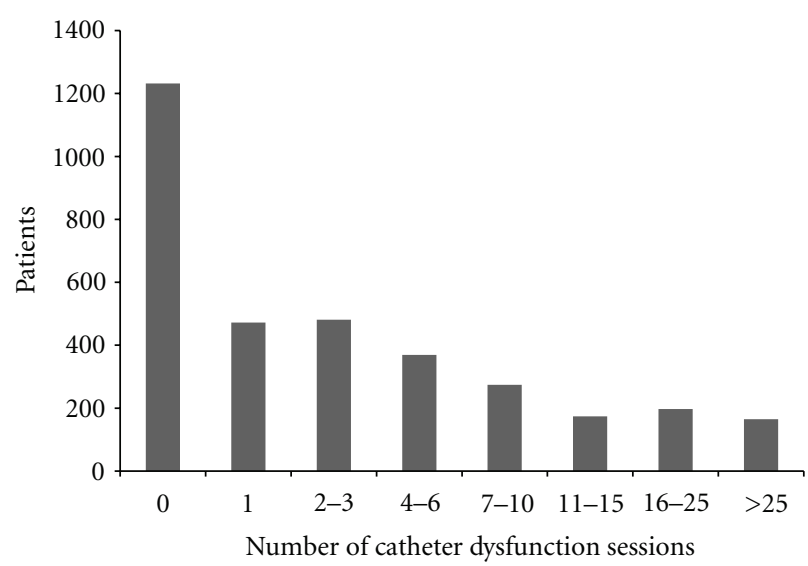

Figure 5: Frequency of catheter dysfunction Sessions. Catheter dysfunction was defined as unplanned blood flow rate during the dialysis session of $<300 \mathrm{~mL} / \mathrm{min}$.

In spite of these limitations, our findings suggest that catheter hemodialysis BFR $<300 \mathrm{~mL} / \mathrm{min}$ is common in routine dialysis care and that it impacts on the provision of dialysis services, as well as catheter-related procedures and medical costs. It is uncertain how much of the disruption in dialysis services and utilization of medical services was based solely on the perceived need to maintain BFR $>300 \mathrm{~mL} / \mathrm{min}$ to ensure adequate dialysis and how much was based on observed problems with dialysis adequacy.

\section{Acknowledgments}

The authors gratefully acknowledge the editorial assistance of Kim Merjan. Funding for licensing the data used in this study was provided to Outcomes Insights and Denver Nephrologists by Genentech. However, the funder played no role in design and conduct of the study; collection, management, analysis, and interpretation of the data; or preparation, review, or approval of the paper. R. I. Griffiths and M. D.
Danese are employees of Outcomes Insights. R. J. Herbert is a consultant to Outcomes Insights. B. B. Newsome and G. A. Block are employees of Denver Nephrologists.

\section{References}

[1] L. M. Moist, B. R. Hemmelgarn, and C. E. Lok, "Relationship between blood flow in central venous catheters and hemodialysis adequacy," Clinical Journal of the American Society of Nephrology, vol. 1, no. 5, pp. 965-971, 2006.

[2] Vascular Access Work Group, "Clinical practice guidelines for vascular access," American Journal of Kidney Diseases, vol. 48, supplement 1, pp. S248-S273, 2006.

[3] M. R. Chan, "Hemodialysis central venous catheter dysfunction," Seminars in Dialysis, vol. 21, no. 6, pp. 516-521, 2008.

[4] K. D. Bolz, G. Fjermeros, T. E. Wideroe, and S. Hatlinghus, "Catheter malfunction and thrombus formation on doublelumen hemodialysis catheters: an intravascular ultrasonographic study," American Journal of Kidney Diseases, vol. 25, no. 4, pp. 597-602, 1995.

[5] O. Negulescu, M. Coco, J. Croll, and M. H. Mokrzycki, "Large atrial thrombus formation associated with tunneled cuffed hemodialysis catheters," Clinical Nephrology, vol. 59, no. 1, pp. 40-46, 2003.

[6] Z. J. Twardowski, "The clotted central vein catheter for haemodialysis," Nephrology Dialysis Transplantation, vol. 13, no. 9, pp. 2203-2206, 1998.

[7] M. A. Little, A. O'Riordan, B. Lucey et al., "A prospective study of complications associated with cuffed, tunnelled haemodialysis catheters," Nephrology Dialysis Transplantation, vol. 16, no. 11, pp. 2194-2200, 2001.

[8] R. Ponikvar and J. Buturović-Ponikvar, "Temporary hemodialysis catheters as a long-term vascular access in chronic hemodialysis patients," Therapeutic Apheresis and Dialysis, vol. 9, no. 3, pp. 250-253, 2005.

[9] Centers for Medicare and Medicaid Services, https://www.cms .gov/CPMProject/.

[10] U.S. Renal Data System, "USRDS 2009 Annual Data Report: Atlas of Chronic Kidney Disease and End-Stage Renal Disease in the United States," National Institutes of Health, National Institute of Diabetes and Digestive and Kidney Diseases, Bethesda, Md, USA, 2009, http://www.usrds.org/2009/rg/A intro_sec_1_10.pdf.

[11] United States Renal Data System, "Incident and Prevalent counts by quarter," Minneapolis, Minn, USA, http://www .usrds.org/qtr/default.html.

[12] M. E. Charlson, P. Pompei, K. A. Ales, and C. R. MacKenzie, "A new method of classifying prognostic comorbidity in longitudinal studies: development and validation," Journal of Chronic Diseases, vol. 40, no. 5, pp. 373-383, 1987.

[13] SAS Institute Inc., "SAS 9.1.3 Help and Documentation," Cary, NC, USA, SAS Institute Inc., 2000-2004. 


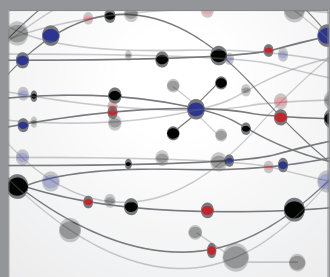

The Scientific World Journal
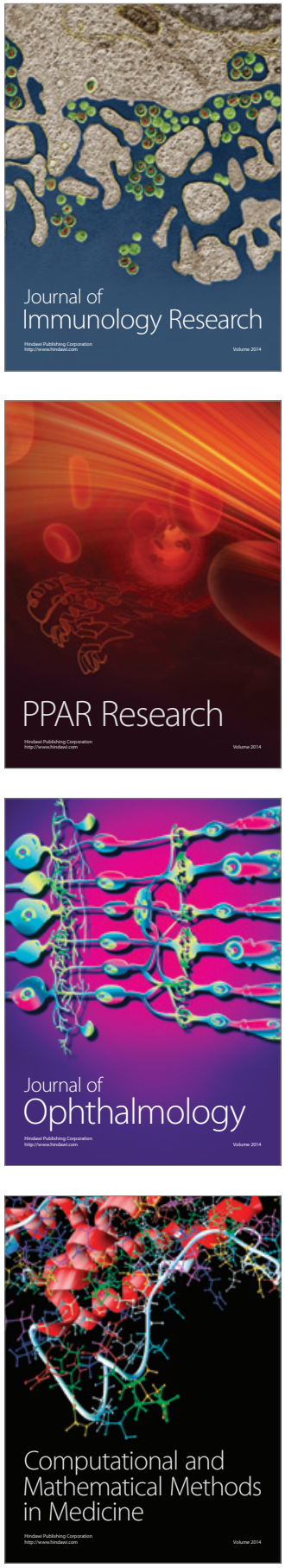

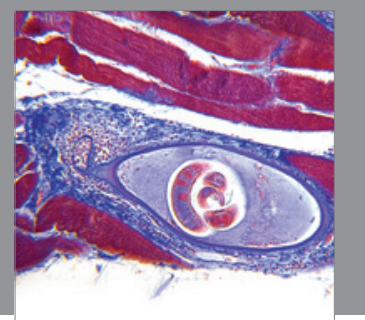

Gastroenterology

Research and Practice
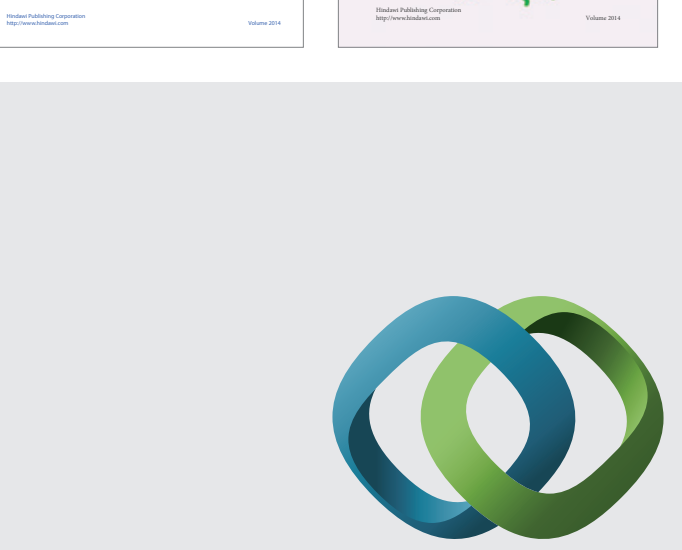

\section{Hindawi}

Submit your manuscripts at

http://www.hindawi.com
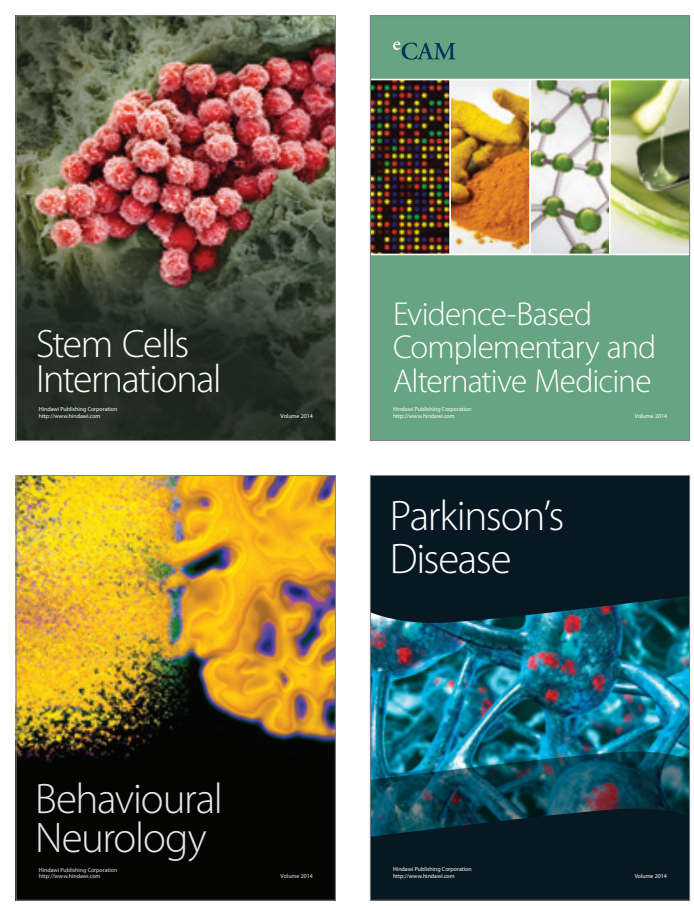

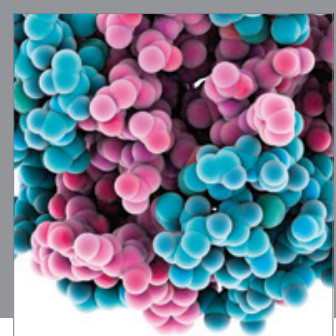

Journal of
Diabetes Research

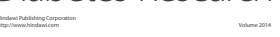

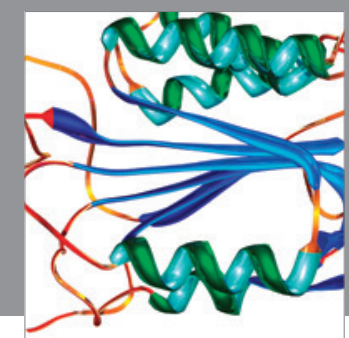

Disease Markers
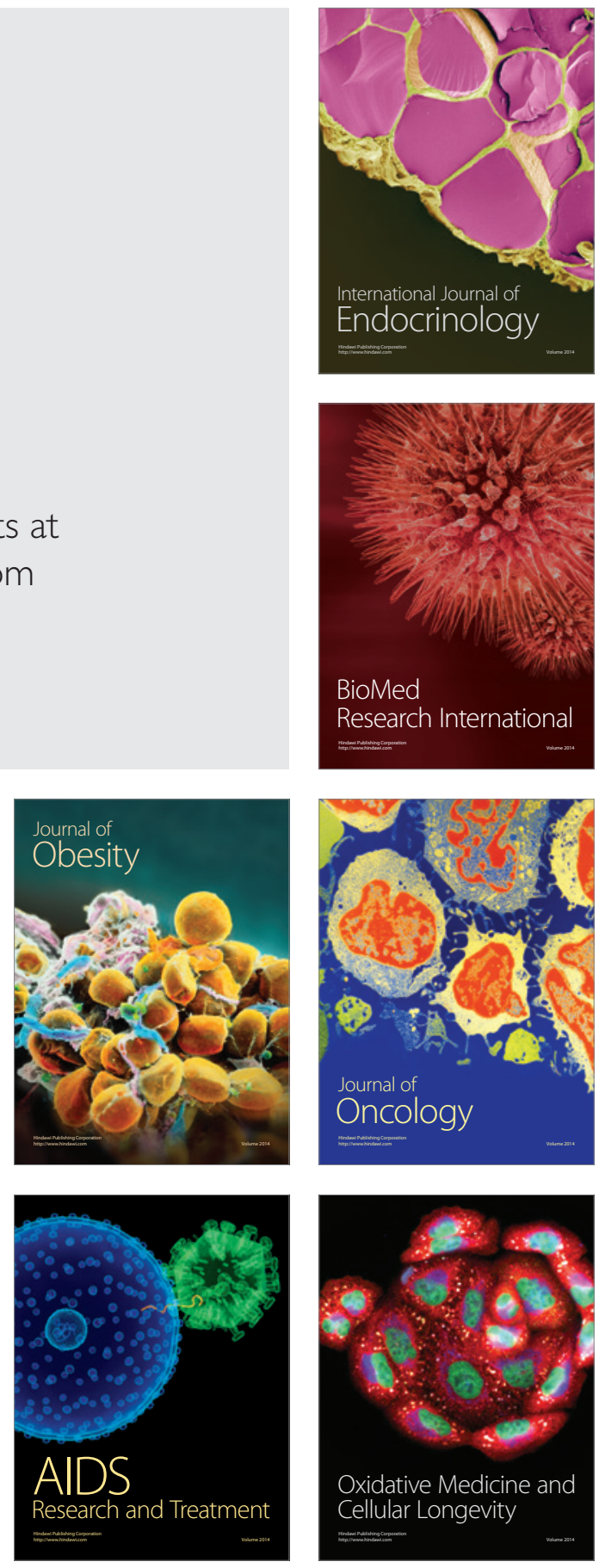